\title{
Technical and Clinical Aspects of Diagnostic Single-Balloon Enteroscopy in the First Decade of Use: A Systematic Review and Meta-analysis
}

\author{
Ye Gao, Lei Xin, Yi-Tong Zhang, Xiao-Rong Guo, Qian-Qian Meng, Zhao-Shen Li, and Zhuan Liao \\ Department of Gastroenterology, Changhai Hospital, Naval Medical University, Shanghai, China
}

\section{Article Info}

Received October 14, 2019

Revised March 14, 2020

Accepted March 25, 2020

Published online October 8, 2020

Corresponding Author

Zhao-Shen Li

ORCID https://orcid.org/0000-0002-1650-4014

E-mail zhaoshen-li@hotmail.com

Zhuan Liao

ORCID https://orcid.org/0000-0002-2595-966X

E-mail zhuanleo@126.com

Ye Gao, Lei Xin, Yi-Tong Zhang, and Xiao-Rong Guo contributed equally to this work as first authors.

\begin{abstract}
Background/Aims: Single-balloon enteroscopy (SBE) has been widely used in diagnosing small bowel disease. We conducted this study to systematically appraise its technical and clinical performance.

Methods: Studies on SBE published by September 2018 were systematically searched. Technical and clinical performance data were collected and analyzed with descriptive or meta-analysis methods.

Results: In total, 54 articles incorporating 4,592 patients (6,036 procedures) were included. Regarding technical parameters, the pooled insertion depths (IDs) for anterograde and retrograde SBE were $209.2 \mathrm{~cm}$ and $98.1 \mathrm{~cm}$, respectively. The pooled retrograde ID in Asian countries was significantly greater than that in Western countries $(129.0 \mathrm{~cm}$ vs $81.1 \mathrm{~cm}, p<0.001)$. The pooled anterograde and retrograde procedure times were 57.6 minutes and 65.1 minutes, respectively. The total enteroscopy rate was $21.9 \%$, with no significant difference between Asian and Western countries. Clinically, the pooled diagnostic yield of SBE was $62.3 \%$. Obscure gastrointestinal bleeding (OGIB) was the most common indication (50.0\%), with a diagnostic yield of $59.5 \%$. Vascular lesions were the most common findings in Western OGIB patients $(76.9 \%)$ but not in Asian ones (31.0\%). The rates of severe and mild adverse events were $0.5 \%$ and $2.5 \%$, respectively.

Conclusions: SBE is technically efficient and is clinically effective and safe, but total enteroscopy is relatively difficult to achieve with this technique. Etiologies of OGIB in Asian countries differ from those in Western countries. (Gut Liver 2021;15:262-272)
\end{abstract}

Key Words: Single-balloon enteroscopy; Systematic review; Meta-analysis; Diagnosis; Total enteroscopy

\section{INTRODUCTION}

Up until the beginning of the current millennium, the small intestine had long been considered a black box for digestive endoscopy because of its depth, length and various loops. ${ }^{1}$ In 2000 and the following year, the invention of capsule endoscopy (CE) and double-balloon enteroscopy (DBE) enabled whole small-bowel visualization from different approaches. ${ }^{2,3}$ Clinical studies have proved the detectability and safety of DBE as well as its ability to perform therapeutic procedures. ${ }^{4}$ Despite its wide clinical application, DBE was found to have some technical issues, including complex, cumbersome preparation and handling.
Single-balloon enteroscopy (SBE) system was developed in 2006 as a simplified version and was clinically approved in 2007. ${ }^{1}$ Utilizing one balloon on the tip of the overtube, SBE system has been thought to be associated with shorter preparation time and easier handling. ${ }^{5}$ Up to now, SBE has been widely used and regarded as an alternative to DBE for patients with suspected small bowel disease. ${ }^{6}$

Technical parameters and clinical performance of SBE are of great interests for endoscopists around the world. In the past decade, a considerable number of studies on SBE have been published. However, some studies were of small sample sizes and to some extent showed inconsistent results, especially regarding insertion depth (ID) and 
total enteroscopy rate. So far, there has been no systematic review and meta-analysis that evaluates the overall performance of SBE as a diagnostic instrument. We therefore performed this systematic review and meta-analysis to include all eligible publications on diagnostic SBE to summarize its indications, positive findings and adverse events (AEs) and to provide pooled data on total procedure time, ID, diagnostic yield and total enteroscopy rate.

\section{MATERIALS AND METHODS}

\section{Search strategy}

This study was performed and reported in accordance with the Preferred Reporting Items for Systematic Reviews and Meta-Analyses (Supplementary File 1). The literature search was performed in PubMed, Embase and Cochrane Library on December 15, 2019 aiming for retrieving all studies relevant to SBE. The full electronic search strategy used in PubMed was: ("single-balloon enteroscopy" OR "single-balloon enteroscope" OR "single-balloon endoscopy" OR "single-balloon endoscope" OR "small bowel enteroscopy" OR "small bowel endoscopy” OR “deep enteroscopy" OR "balloon-assisted enteroscopy" OR “balloon-assisted endoscopy”) AND (“2006/12/31”[Date Publication]: “2019/12/15”[Date - Publication]).

\section{Inclusion and exclusion criteria}

All publications retrieved were reviewed by titles and abstracts. Original articles that potentially contained data on technical or clinical aspects of diagnostic SBE were included. Full texts were subsequently obtained and reviewed to determine the final inclusions or exclusions. Articles that contained other diagnostic instruments such as CE, DBE or spiral enteroscopy were included, but only SBE-related data were used. Abstracts containing available data that met with the study purpose were also included. Only studies published in English were included. Exclusion criteria were: (1) publications do not contain original data including case reports, reviews, guideline/consensus articles, systematic reviews and meta-analyses, comments, and news; (2) SBEs were performed merely for therapeutic purposes such as jejunostomy, balloon dilation, polypectomy or SBE-assisted endoscopic retrograde cholangiopancreatography; (3) studies using modified SBE such as ultrathin SBE or capassisted SBE; (4) SBEs were performed not for small bowel diseases; or (5) for multiple studies with the same dataset, only the study with the largest sample size was included. The search process is outlined in detail in Fig. 1.

\section{Definition}

Diagnostic SBE was defined as procedures using SBE system mainly for diagnostic purposes. Indications were valid medical reasons to perform SBE. Obscure gastrointestinal bleeding (OGIB) was defined as occult or overt bleeding of unknown origin that persisted or recurred after an initial negative colonoscopy and esophagogastroduodenoscopy. ${ }^{7,8}$ Crohn's disease referred to established or

857 Publications identified by the search strategy

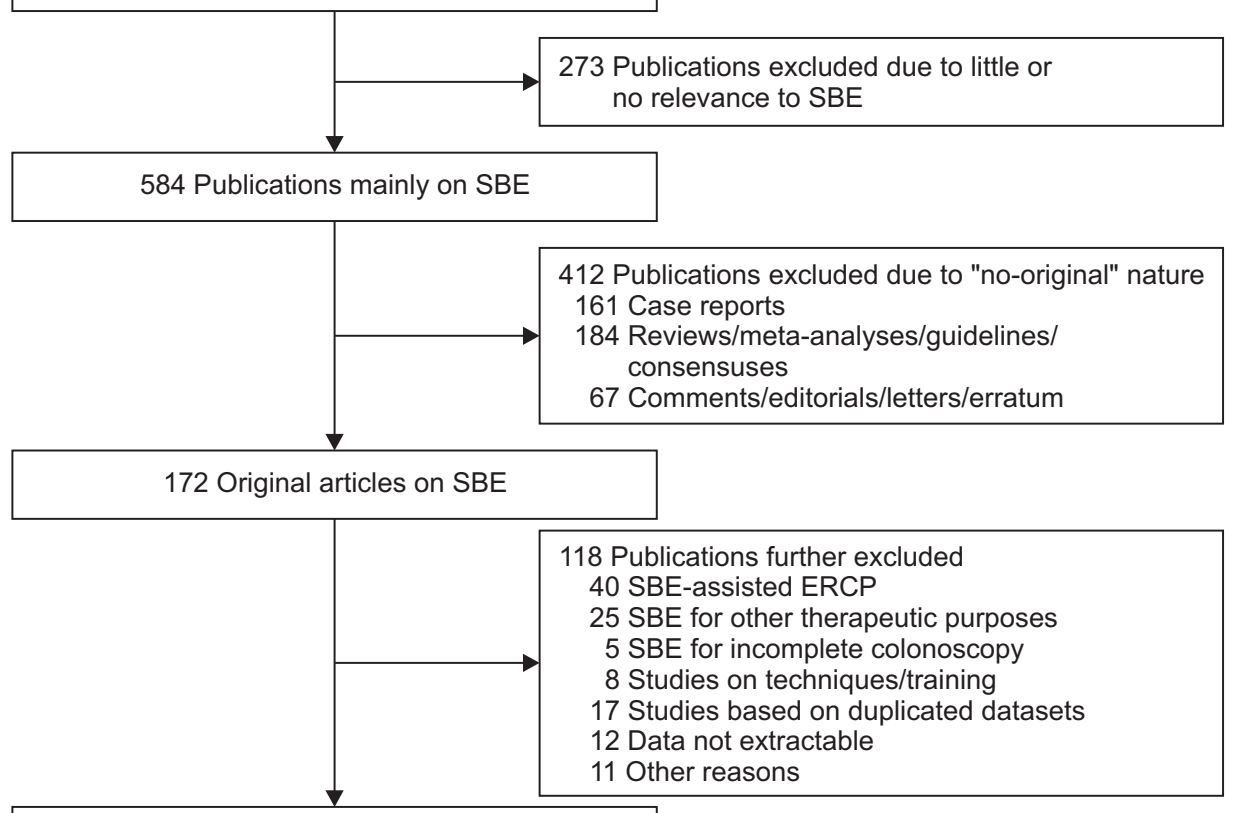

54 Original articles for final analysis
Fig. 1. Flowchart of the literature search process.

SBE, single-balloon enteroscopy; ERCP, endoscopic retrograde cholangiopancreatography. 
clinically suspected Crohn's disease based on the clinical course or colonoscopy findings. ${ }^{9}$ Celiac disease included established disease based on duodenal biopsy or suspected disease based on weight loss, anemia, diarrhea, and other symptoms triggered by dietary gluten. ${ }^{10}$ Neoplastic lesions were defined as suspected small-bowel tumors or polyposis. ${ }^{11}$ Small bowel obstruction was consistent with the presence of abdominal pain, vomiting, bloating or related imaging suggesting complete or partial blockage of the small bowel. ${ }^{12}$ Any persistent or recurred abdominal pain or diarrhea with unclear reasons after colonoscopy and esophagogastroduodenoscopy and cannot be classified as previous categories were defined as unexplained abdominal pain and unexplained diarrhea, respectively. Abnormal test results were defined as suspected small bowel lesions found in other examinations (CE, computed tomography, magnetic resonance, etc) and cannot be classified as previous categories. Indications not stated above were classified as others.

For anterograde SBE, ID was defined as distance of insertion distal to the ligament of Treitz or the pylorus according to different definitions in each included study. For retrograde SBE, ID was defined as distance of insertion proximal to the ileocecal valve. Total enteroscopy was defined when the entire small bowel was successfully observed. The total enteroscopy rate was calculated as the ratio of patients with successful total enteroscopy to all patients in whom entire small bowel visualization was attempted. $^{4}$

For each study, the diagnostic yield was calculated as ratio of patients with significant enteroscopic findings to total patient numbers. Enteroscopic findings were further classified into five broad categories based on the typical pattern of most publications, ${ }^{4}$ that is, inflammatory lesions (including Crohn's disease, erythema, erosions, ulcers, benign strictures, etc.), vascular lesions (including angiectasis, arteriovenous malformation, varix, Dieulafoy's lesions, etc.), neoplastic lesions (benign or malignant tumors or polyps), diverticula, and others.

AEs of SBE referred to any untoward medical occurrence that happened during and after the procedures and were divided into mild and severe categories. The former included transient symptoms such as abdominal pain, nausea, vomiting, abdominal distension, and other selflimiting conditions. The latter referred to severe conditions that required hospitalization and/or endoscopic or surgical intervention and/or contributed to the death of the patient.

\section{Data extraction and quality assessment}

Full texts of all eligible articles were reviewed for data extraction. For each study, the total numbers of patients and SBE procedures were collected, followed by patients' baseline characteristics, technical information of SBE, total enteroscopy rate, enteroscopic findings, diagnostic yields and AEs. Missing data or vague definitions were resolved by direct contact with authors if possible. Two authors (Y.G. and Y.T.Z.) identified eligible articles and extracted the data independently, whereas a third author (L.X.) checked the results. Discrepancies were solved by consensus. Two independent authors (Y.G. and X.R.G.) used the critical appraisal tool of Munn et al., ${ }^{13}$ which was designed for systematic reviews of prevalence and incidence data, to assess the quality of included studies (Supplementary File 2). Studies fulfilling all applicable quality criteria were classified as high-quality studies.

\section{Statistical analysis}

Study characteristics, compositions of indications and enteroscopic findings and $\mathrm{AE}$ rates were summarized by descriptive methods. Pooled results of IDs, total procedure time, total enteroscopy rate and diagnostic yield were computed through meta-analyses. Heterogeneity among studies was identified by Cochran's $\mathrm{Q}$ test ( $\mathrm{p}<0.1$ to be statistically significant). $\mathrm{I}^{2}$ statistic was used to further quantify the heterogeneity. A fixed or random effects model was used to pool the data when there was non-significant or significant heterogeneity.

As was shown in published studies, meta-analyses based on single-arm data were likely to exhibit high levels of heterogeneity. ${ }^{14,15}$ Subgroup analyses were therefore designed to evaluate the origins of heterogeneity and to discover potential correlations between study characteristics and results. We prespecified five subgroups based on time of publication (before 2013 or in \& after 2013), region where the study was conducted (Asian countries or Western countries), study design (prospective studies or others), sample size (greater than 100 or not) and study quality (high-quality studies or others). In this study, Western countries referred to European, North American countries and Australia. We designed this subgroup because the total enteroscopy rate and composition of small-bowel disease were reported to be different in several studies. A test of interaction was used to compare the difference between pooled subgroup results. Sensitivity analysis was performed to evaluate the robustness of results, in which pooled estimates were computed omitting one study in each turn. The potential presence of publication bias was evaluated statistically by the Begg-Mazumdar's and Egger's test. All statistical analyses were performed with Stata software version 12.0 (StataCorp, College Station, TX, USA). Other than in Cochran's $Q$ test, a p-value less than 0.05 was considered to be statistically significant. 


\section{RESULTS}

\section{Study characteristics}

A total of 857 publications were initially retrieved by literature search. The detailed process of literature search and selection is outlined in Fig. 1. After reviewing the full texts of 172 original articles, 54 studies involving 4,592 patients $(6,036$ procedures) were included in the final analysis. SBE system SIF-Q180, SIF-Q260, XSIF-Q260Y, and XSIFQ160Y were included in this analysis. Single-balloon technique of the DBE system was used in one study. ${ }^{16}$ Of the 54 studies, 22 studies (40.7\%) were published before 2013, 35 studies $(64.8 \%)$ had a sample size smaller than 100 (patients), 18 studies (33.3\%) were prospectively designed. Regarding regions of studies, 23 studies (42.6\%) were conducted in Asia while 17 (31.5\%) in Europe, 13 (24.1\%) in North America and one (1.9\%) in Australia. After quality assessment, 20 studies (37.0\%) were classified as highquality studies. Detailed characteristics and quality assessment of studies included in the systematic review could be found in the Supplementary Files 2 and 3.

\section{Indications}

Indications for SBE were reported in 43 articles including 3,865 patients. A total of 1,931 patients (50.0\%) were referred to SBE due to OGIB. Following indications included Crohn's disease (13.9\%), unexplained abdominal pain (13.0\%), neoplastic lesions $(7.0 \%)$, unexplained diarrhea (6.1\%), abnormal test results $(2.7 \%)$, celiac disease $(1.3 \%)$ and small bowel obstruction (1.3\%). Furthermore, 181 patients $(4.7 \%)$ were categorized into other indications.

\section{Technical parameters}

The anterograde IDs were reported as distances beyond the ligament of Treitz in seven studies (607 procedures) and distances beyond the pylorus in four studies (396 procedures), with pooled IDs being $209.2 \mathrm{~cm}$ (95\% confidence interval [CI], 170.9 to $247.5 \mathrm{~cm}$ ) and $216.4 \mathrm{~cm}$ (95\% CI, 182.2 to $250.7 \mathrm{~cm}$ ), respectively. Incorporating 14 studies with 753 procedures, the pooled retrograde ID was calculated to be $98.1 \mathrm{~cm}$ (95\% CI, 84.3 to $111.8 \mathrm{~cm})$. Subgroup analysis revealed that the pooled ID of retrograde SBE was significantly longer in Asian country studies than in Western studies $(129.0 \mathrm{~cm}$ vs $81.1 \mathrm{~cm}, \mathrm{p}<0.001)$. Subgroup analysis for anterograde SBE was not performed because of

Table 1. Pooled ID of Single-Balloon Enteroscopy from Different Approaches and Subgroup Analyses

\begin{tabular}{|c|c|c|c|c|c|c|}
\hline \multirow{2}{*}{ Enteroscopic approaches } & \multirow{2}{*}{$\begin{array}{l}\text { No. of studies } \\
\text { (procedures) }\end{array}$} & \multirow{2}{*}{ Pooled ID (cm) } & \multirow{2}{*}{$95 \% \mathrm{Cl}(\mathrm{cm})$} & \multirow{2}{*}{ p-value* } & \multicolumn{2}{|c|}{ Heterogeneity } \\
\hline & & & & & $p$-value ${ }^{\dagger}$ & $1^{2} \%$ \\
\hline Oral approach (LOT) ${ }^{\ddagger}$ & $7(607)$ & 209.2 & $170.9-247.5$ & - & $<0.001$ & 97.8 \\
\hline Oral approach (pylorus) & $4(396)$ & 216.4 & $182.2-250.7$ & - & $<0.001$ & 92.8 \\
\hline Anal approach & 14 (753) & 98.1 & $84.3-111.8$ & - & $<0.001$ & 92.1 \\
\hline Asian countries & $5(193)$ & 129.0 & $111.1-146.8$ & $<0.001$ & $<0.001$ & 80.9 \\
\hline Western countries & $9(560)$ & 81.1 & $71.9-90.3$ & - & $<0.001$ & 73.8 \\
\hline
\end{tabular}

ID, insertion depth; $\mathrm{Cl}$, confidence interval; LOT, ligament of Treitz.

${ }^{*}$ p-value for subgroup comparisons; ${ }^{\dagger} p$-value for Cochran's $Q$ tests; ${ }^{\ddagger} \mathrm{ID}$ was calculated as the distance beyond the LOT; ${ }^{\S} \mathrm{ID}$ was calculated as the distance beyond the pylorus.

Table 2. Pooled Total Procedure Times of Single-Balloon Enteroscopy from Different Approaches and Subgroup Analyses

\begin{tabular}{|c|c|c|c|c|c|c|}
\hline \multirow{2}{*}{ Enteroscopic approaches } & \multirow{2}{*}{$\begin{array}{l}\text { No. of studies } \\
\text { (procedures) }\end{array}$} & \multirow{2}{*}{$\begin{array}{c}\text { Pooled } \\
\text { procedure } \\
\text { time (min) }\end{array}$} & \multirow{2}{*}{$\begin{array}{c}95 \% \mathrm{Cl} \\
\text { (min) }\end{array}$} & \multirow{2}{*}{$\mathrm{p}$-value* } & \multicolumn{2}{|c|}{ Heterogeneity } \\
\hline & & & & & p-value ${ }^{+}$ & $\mathrm{I}^{2} \%$ \\
\hline Oral approach & $22(1,635)$ & 57.6 & $52.6-62.6$ & & $<0.001$ & 97.1 \\
\hline Asian countries & $11(540)$ & 65.2 & $55.2-75.3$ & 0.012 & $<0.001$ & 95.4 \\
\hline Western countries & $11(1,095)$ & 50.8 & $45.7-55.9$ & & $<0.001$ & 97.7 \\
\hline Published before 2013 & 11 (539) & 62.5 & $53.7-71.3$ & 0.090 & $<0.001$ & 96.1 \\
\hline Published in \& after 2013 & $11(1,096)$ & 53.3 & $47.3-59.2$ & & $<0.001$ & 97.2 \\
\hline Anal approach & $21(1,011)$ & 65.1 & $59.3-71.0$ & & $<0.001$ & 95.6 \\
\hline Asian countries & 11 (403) & 71.1 & $62.5-79.4$ & 0.012 & $<0.001$ & 94.4 \\
\hline Western countries & $10(608)$ & 57.6 & $51.3-63.9$ & & $<0.001$ & 92.2 \\
\hline Published before 2013 & 9 (269) & 69.8 & $60.7-78.9$ & 0.152 & $<0.001$ & 92.2 \\
\hline Published in \& after 2013 & $12(742)$ & 61.5 & $54.7-68.3$ & & $<0.001$ & 95.4 \\
\hline
\end{tabular}

$\mathrm{Cl}$, confidence interval.

*p-value for subgroup comparisons; ${ }^{\dagger} \mathrm{p}$-value for Cochran's $\mathrm{Q}$ tests. 
the small number of included studies.

The pooled total procedure durations were $57.6 \mathrm{~min}$ utes (95\% CI, 52.6 to 62.6 minutes) and 65.1 minutes (95\% CI, 59.3 to 71.0 minutes) for anterograde and retrograde SBE, respectively. Subgroup analyses showed that studies conducted in Asian countries were associated with significantly longer procedure durations for both oral and anal approaches. Moreover, a trend of shorter procedure durations was found in studies conducted in \& after year 2013, although statistical non-significant. Pooled results and subgroup analyses on SBE technical parameters were shown in detail in Tables 1 and 2.

\section{Total enteroscopy rate}

After reviewing the full texts, 18 studies with 132 total enteroscopy and 508 attempts were incorporated. The rates of total enteroscopy ranged from $0.0 \%$ to $71.4 \%$ among different studies and the pooled rate was $21.9 \%$ (95\% CI, $12.0 \%$ to $33.3 \%$ ) with an $\mathrm{I}^{2}$ statistic of $81.47 \%$, indicating a high degree of heterogeneity (Fig. 2). Studies conducted in Asian and Western countries showed similar pooled total enteroscopy rates $(22.3 \%$ vs $22.4 \%, \mathrm{p}=0.881)$. A trend was observed that articles published in \& after 2013 showed higher pooled total enteroscopy rate compared to studies published before 2013 (31.6\% vs $14.6 \%, \mathrm{p}=0.076$ ), although statistically non-significant (Supplementary File 4).

\section{Diagnostic yields}

Based on 35 studies containing 3,062 patients, the pooled diagnostic yield was $62.3 \%$ (95\% CI, 58.0\% to $66.5 \%$ ) (Fig. 3). Subgroup analysis showed no significant difference between Asian and Western countries (61.3\% vs $62.9 \%, \mathrm{p}=0.813)$. In those included studies, Western countries mainly consist of North American and European countries. When considering specific continents, the pooled diagnostic yields were $57.1 \%$ (95\% CI, 53.7\% to $60.4 \%), 61.3 \%$ (95\% CI, $54.3 \%$ to $68.1 \%$ ) and $72.0 \%$ (95\% CI, 63.5\% to 79.9\%) for North American, Asian and European countries, respectively. Pooled diagnostic yield from European studies was significantly higher than that from North American studies ( $p=0.002, \alpha=0.017$ for multiplicity adjustment). Diagnostic yields among North American studies showed non-significant heterogeneity $\left(\mathrm{I}^{2}=0.0 \%, \mathrm{p}=0,660\right)$ (Supplementary File 5$)$. Regarding specific indications (Table 3 ), the pooled diagnostic yield was highest in patients with suspected or confirmed neoplastic lesions (91.1\%) and lowest in unexplained abdominal pain (55.0\%).

\section{Composition of positive findings}

Compositions of positive findings were reported in 39 articles. Inflammatory lesions accounted for the largest proportion $(50.0 \%, \mathrm{n}=1,017)$, followed by vascular lesions $(25.5 \%, \mathrm{n}=518)$, neoplastic lesions $(16.4 \%, \mathrm{n}=333)$, diver-

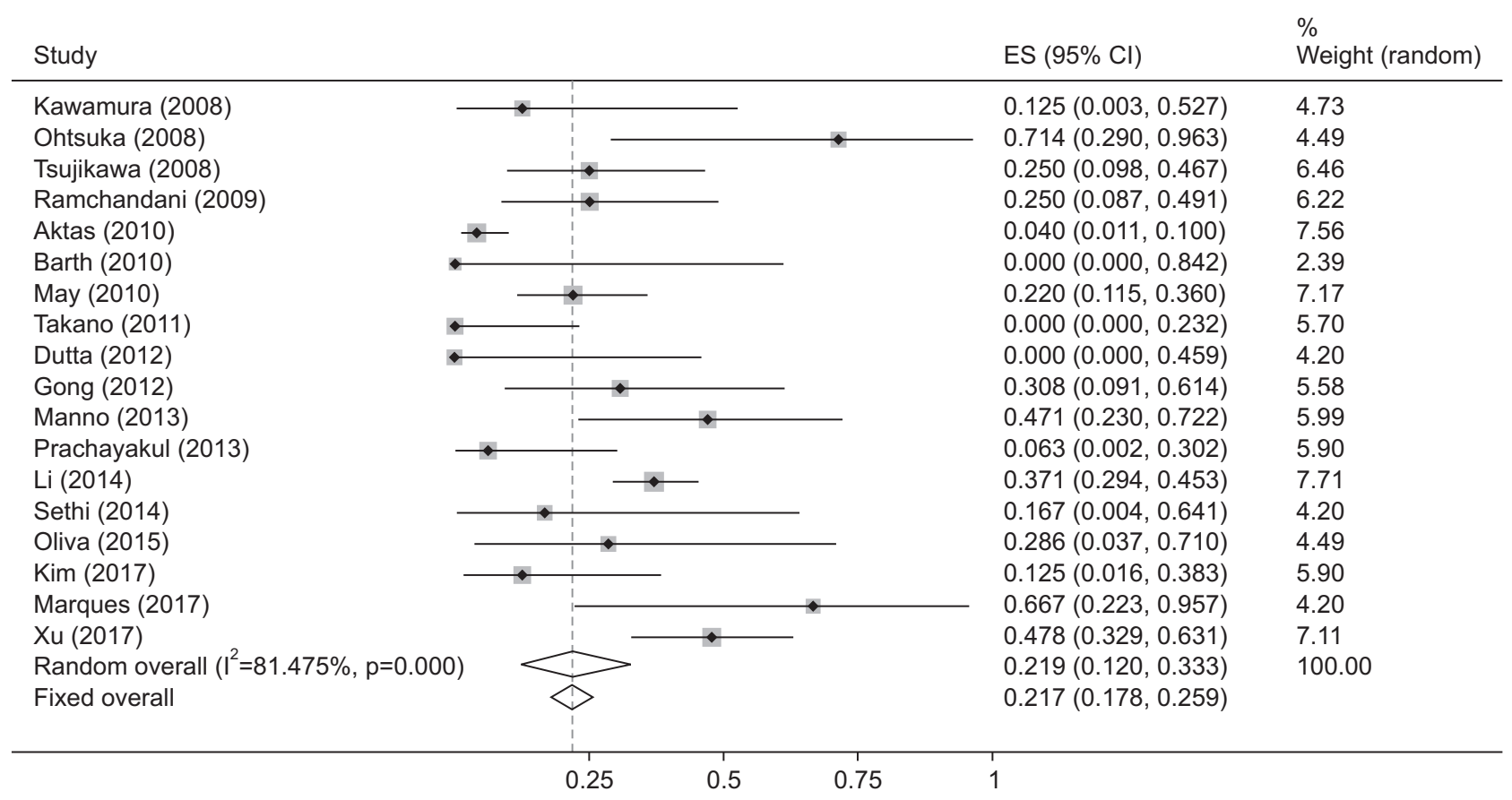

Fig. 2. Forest plot showing the total enteroscopy rates for all studies included in the meta-analysis and the pooled total enteroscopy rates calculated by random and fixed effects models. ${ }^{1,16,20-24,30,32,35-43}$

$\mathrm{ES}$, effect size; $\mathrm{Cl}$, confidence interval. 


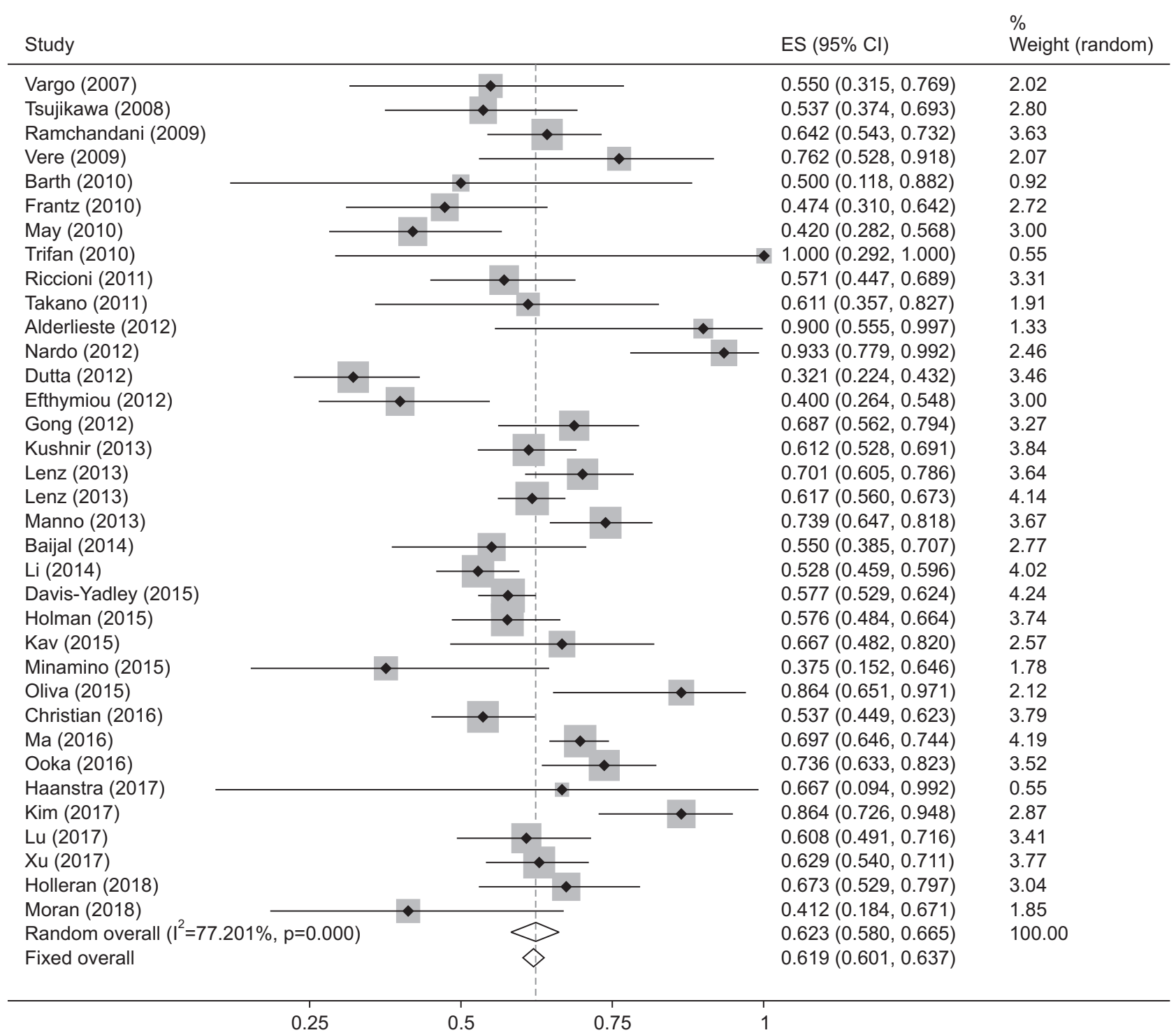

Fig. 3. Forest plot showing the diagnostic yields of all studies included in the meta-analysis and the pooled diagnostic yields calculated by random and fixed effects models. ${ }^{1,9,10,16,17,19-22,25,30,32,37-40,42,44-61}$

$\mathrm{ES}$, effect size; $\mathrm{Cl}$, confidence interval.

Table 3. Pooled Diagnostic Yields According to Indications

\begin{tabular}{|c|c|c|c|c|c|}
\hline \multirow[b]{2}{*}{ Indications } & \multirow{2}{*}{$\begin{array}{c}\text { No. of } \\
\text { studies } \\
\text { (total } \\
\text { cases) }\end{array}$} & \multirow{2}{*}{$\begin{array}{c}\text { Pooled } \\
\text { detection } \\
\text { rate, } \%\end{array}$} & \multirow[b]{2}{*}{$95 \% \mathrm{Cl}$} & \multicolumn{2}{|c|}{ Heterogeneity } \\
\hline & & & & $p$-value & $1^{2} \%$ \\
\hline OGIB & 17 (913) & 59.5 & $51.7-67.1$ & $<0.001$ & 79.4 \\
\hline Crohn's disease & 8 (363) & 75.5 & $53.6-92.8$ & $<0.001$ & 90.8 \\
\hline $\begin{array}{l}\text { Unexplained } \\
\text { abdominal pain }\end{array}$ & $5(84)$ & 55.0 & $36.6-72.8$ & 0.052 & 57.3 \\
\hline $\begin{array}{l}\text { Unexplained } \\
\text { diarrhea }\end{array}$ & $5(54)$ & 56.1 & $37.3-74.1$ & 0.239 & 27.3 \\
\hline $\begin{array}{l}\text { Neoplastic } \\
\text { lesions }\end{array}$ & $5(30)$ & 91.1 & $74.2-100.0$ & 0.557 & 0.0 \\
\hline
\end{tabular}

$\mathrm{Cl}$, confidence interval; OGIB, obscure gastrointestinal bleeding. *p-value for Cochran's Q tests. ticula $(3.5 \%, \mathrm{n}=72)$ and other findings $(4.7 \%, \mathrm{n}=95)$. When the calculation was specific to OGIB, vascular lesions became the most common findings $(43.3 \%, \mathrm{n}=210)$, followed by inflammatory lesions $(32.6 \%, \mathrm{n}=158)$, neoplastic lesions $(12.8 \%, \mathrm{n}=62)$, diverticulum $(6.2 \%, \mathrm{n}=30)$ and others $(5.2 \%, n=25)$. Moreover, the compositions of findings in OGIB patients were different between Asian and Western countries, with inflammatory lesions (39.7\%) and vascular lesions $(76.9 \%)$ accounting for the largest proportions, respectively (Fig. 4).

\section{Adverse events}

Severe and mild AE rates of SBE calculated by descriptive method were $0.5 \%(26 / 4,984)$ and $2.5 \%(94 / 3,728)$, re- 
spectively. Severe AE rates from individual studies ranged from $0 \%$ to $3.6 \%$ and were lower than $1 \%$ in 31 studies (79.5\%). A total of 26 severe AEs were reported, including 11 perforations, nine acute pancreatitis, three severe mucous lacerations, two major bleedings, and one hypotension after anesthesia. Mild $\mathrm{AE}$ rates ranged from $0 \%$ to 47.1\%. Mild AE rates were lower than $10 \%$ in 25 studies (83.3\%) and lower than 5\% in 22 studies (73.3\%). A total of 94 mild AEs were reported including 34 abdominal pain or discomfort, 31 hyperamylasemia, 11 mild mucous lacerations, four sore throats, four mild mucous bleedings, four anesthesia related conditions, and three cardiac arrhythmias.

\section{Additional analysis}

Subgroup analyses showed significant differences or obvious numerical trends were reported in previous sections. The robustness of pooled results of total enteroscopy rate and pooled diagnostic yield were further confirmed by sensitivity analyses. No evidence of significant publication bias was found by the Begg-Mazumdar's and Egger's test. Figures for additional analyses including subgroup and sensitivity analyses could be found in Supplementary Files 4 and 5.

\section{DISCUSSION}

This study provides a systematic review and metaanalysis on the overall technical and clinical performance of diagnostic SBE during its first decade of use. The SBE system was introduced as a simplified version of DBE to facilitate handling and shorten preparation and procedure time. ${ }^{16-18}$ The current study showed that the pooled total procedure time for anterograde and retrograde SBE were

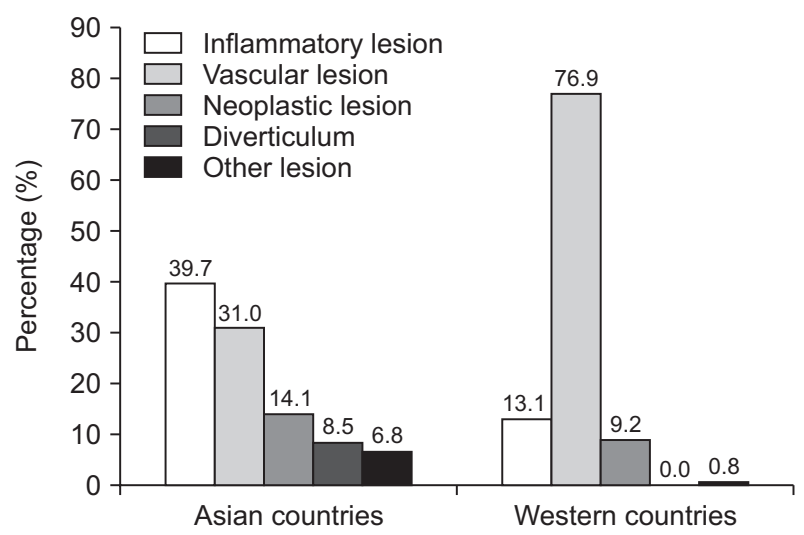

Fig. 4. Compositions of enteroscopic findings in patients with obscure gastrointestinal from Asian or Western countries.
57.6 minutes and 65.1 minutes, respectively. These results were numerically comparable with data from a systematic review of Lenz and Domagk, ${ }^{17}$ which reported the procedure durations for anterograde and retrograde SBE to be $59.8 \pm 10.0$ minutes and $68.8 \pm 10.3$ minutes, respectively. Furthermore, they reported that the procedure durations for anterograde and retrograde DBE were $71.6 \pm 5.9 \mathrm{~min}$ utes and $84.5 \pm 7.6$ minutes, suggesting that DBE may be more time-consuming compared to SBE. Such time-saving nature of SBE was further confirmed by two randomized controlled trials. ${ }^{16,19}$ One of the studies showed the procedure time for anterograde, but not retrograde enteroscopy was significantly decreased in SBE group, ${ }^{16}$ while the other study found a decreased preparation time in SBE group, but no difference in enteroscopic time between SBE and DBE. $^{19}$

Insertability was another major technical concern of SBE. We therefore calculated its pooled total enteroscopy rate $(21.9 \%)$ and IDs for both anterograde $(209.2 \mathrm{~cm}$ beyond the ligament of Treitz and $216.4 \mathrm{~cm}$ beyond the pylorus) and retrograde $(98.1 \mathrm{~cm})$ approaches. Asian countries have been considered to have a higher total enteroscopy rate than Western countries based on a few single-center studies. ${ }^{20-24}$ However, our subgroup results showed no difference in pooled total enteroscopy rates between Asian and Western groups. By literature review, we find that Asian investigators tend to calculate total enteroscopy rates using the number of patients for whom total enteroscopy was attempted as the denominator, which was consistent with the definition in our study, whereas more Western authors tended to use total patient numbers as the denominator. ${ }^{25,26}$ This may contribute to the relative low reported rates in Western studies. However, we did find that studies from Asian countries showed a significantly greater pooled retrograde ID than Western countries $(129.0 \mathrm{~cm}$ vs 81.1 $\mathrm{cm}, \mathrm{p}<0.001$ ). Previous studies showed that female gender, anal insertion route, history of abdomino-pelvic surgery were factors that were associated with decreased ID of balloon-assisted enteroscopy. ${ }^{27,28}$ According to our findings, race might be a new factor that influences retrograde ID. Underlying mechanisms might lie in differences in physique, length of large intestine, etc. for Asians and Caucasians, though further evidences could not be provided.

Without the balloon on the enteroscope tip, SBE uses techniques including additional left-right angulation and suction to hold the small bowel during advancement of the overtube. Theoretically, one might expect that DBE, because of the improved grip on the small bowel, could produce better small-bowel visualization and ID, compared with the SBE technique. Our previous systematic review ${ }^{4}$ showed that the total enteroscopy rate for DBE was $44.0 \%$ 
(569 of 1,143 cases), which was approximately double of SBE (21.9\%). Meta-analyses ${ }^{29,30}$ based on three randomized controlled trials ${ }^{16,31,32}$ also showed the inferiority of SBE to DBE in achieving total enteroscopy. Moreover, the pooled IDs we got in the current study were numerically smaller than published data on DBE $(239.1 \pm 24.3 \mathrm{~cm}$ for oral approach and $129.5 \pm 18.1 \mathrm{~cm}$ for anal approach). ${ }^{17}$ However, a meta-analysis in $2015,{ }^{33}$ based on two randomized controlled trials, ${ }^{19,31}$ showed that no difference in maximal ID was found between DBE and SBE. It should be pointed out that maximal insertion was not attempted in all procedures in included studies. In addition, current methods that measure the ID are all based on the estimation of endoscopists. ${ }^{17}$ Therefore, the clinical significance of those reported IDs should be questioned.

The pooled diagnostic yield of SBE (62.3\%) is comparable to the detection rate of CE (59.4\%) and DBE (68.1\%) reported by our previous systematic reviews, ${ }^{4,7}$ suggesting that SBE is effective to detect small bowel lesions, though with a relatively lower rate to achieve whole small-bowel visualization. Thus, the clinical significance of achieving total enteroscopy or deeper insertion still remains questionable. Future studies should focus on the comparisons of longer-term clinical outcomes between patients in whom total enterosocpy was achieved or not. For patients that do require total enteroscopy or deeper small-bowel insertion, DBE may be the prior choice.

Subgroup analyses showed that pooled diagnostic yield from European countries was higher than those from Asian or North American countries. Diagnostic yields among North American studies showed non-significant heterogeneity $\left(\mathrm{I}^{2}=0.0 \%, \mathrm{p}=0,660\right)$. It should be pointed out that North America includes only two countries, the United States and Canada, in our analyses. Heterogeneity in diagnostic yields among different countries may be due to different compositions of patients, standards of drawing an endoscopic diagnosis, levels of experience of SBE endoscopists, and etc. These results reflect the expected percentages of patients of whom the diagnosis could be clarified after SBE procedure in settings of different continents.

Consistent with other small bowel diagnostic tools including $\mathrm{CE}^{7}$ and $\mathrm{DBE},{ }^{4} \mathrm{OGIB}$ was the most common indication for SBE (50.0\%) with a diagnostic yield of 59.5\%. Patients with different indications exhibited different pooled diagnostic yields, with "suspected small bowel tumor" being the highest (91.1\%) and "unexplained abdominal pain" being the lowest (55.0\%). Patients from different studies had different compositions of indications and this could partly explain the high heterogeneity of diagnostic yields. As for enteroscopic findings, a difference in compositions of OGIB findings between Asian and Western countries was identified, with inflammatory lesions (39.7\%) and vascular lesions (76.9\%) being the most common findings, respectively. This further confirmed the published results from Tanaka et al. ${ }^{34}$ and Xin et al. ${ }^{4}$

There are several limitations to this study. Firstly, the inclusion and exclusion criteria were loosely defined to include all relevant studies. This also gave rise to high levels of heterogeneity among studies. We attempted to identify the origins of heterogeneity by subgroup analyses, but there were likely other factors that could not be identified or controlled based on available data, which might impair the reliability of our study results. Secondly, data from individual studies were reported in different patterns. Although we performed the data extraction process carefully, bias could occur when adjusting those original data to our definitions. Furthermore, we performed single-arm metaanalyses to incorporate all available data on SBE from different study types. However, we could not determine whether such results had any statistical differences compared to other instruments such as DBE or CE.

In conclusion, the SBE system is technically efficient with relatively short procedure duration, but its insertability might be limited. Total enteroscopy is harder to achieve through SBE. In clinical aspects, SBE is effective and safe with acceptable diagnostic yield and AE rates. OGIB was the most common indication. Inflammatory lesions and vascular lesions were the most common enterosopic findings of OGIB in Asian and Western countries, respectively.

\section{CONFLICTS OF INTEREST}

No potential conflict of interest relevant to this article was reported.

\section{AUTHOR CONTRIBUTIONS}

Conceptualization: Y.G., L.X., Z.L., Z.S.L. Data curation: Y.G. Formal analysis: X.R.G., Y.T.Z. Methodology: Q.Q.M., Z.L. Writing - original draft: Y.G., L.X. Writing - review \& editing: Y.G., Y.T.Z., Z.S.L. Approval of final manuscript: all authors.

\section{ORCID}

Ye Gao

Lei Xin

Yi-Tong Zhang

Xiao-Rong Guo
https://orcid.org/0000-0001-6273-880X https://orcid.org/0000-0002-8861-5055 https://orcid.org/0000-0003-4092-8121 https://orcid.org/0000-0002-7606-2174 
Qian-Qian Meng https://orcid.org/0000-0003-3218-3254

Zhao-Shen Li

Zhuan Liao

\section{REFERENCES}

1. Manno M, Barbera C, Bertani H, et al. Single balloon enteroscopy: technical aspects and clinical applications. World J Gastrointest Endosc 2012;4:28-32.

2. Iddan G, Meron G, Glukhovsky A, Swain P. Wireless capsule endoscopy. Nature 2000;405:417.

3. Yamamoto H, Sekine Y, Sato Y, et al. Total enteroscopy with a nonsurgical steerable double-balloon method. Gastrointest Endosc 2001;53:216-220.

4. Xin L, Liao Z, Jiang YP, Li ZS. Indications, detectability, positive findings, total enteroscopy, and complications of diagnostic double-balloon endoscopy: a systematic review of data over the first decade of use. Gastrointest Endosc 2011;74:563-570.

5. Lenz P, Domagk D. Single-balloon enteroscopy. Gastrointest Endosc Clin N Am 2017;27:123-131.

6. Yamamoto H, Ogata H, Matsumoto T, et al. Clinical practice guideline for enteroscopy. Dig Endosc 2017;29:519-546.

7. Liao Z, Gao R, Xu C, Li ZS. Indications and detection, completion, and retention rates of small-bowel capsule endoscopy: a systematic review. Gastrointest Endosc 2010;71:280286.

8. ASGE Standards of Practice Committee, Fisher L, Lee Krinsky M, et al. The role of endoscopy in the management of obscure GI bleeding. Gastrointest Endosc 2010;72:471-479.

9. Holleran G, Valerii G, Tortora A, et al. The use of single balloon enteroscopy in Crohn's disease and its impact on clinical outcome. Scand J Gastroenterol 2018;53:925-929.

10. Kav T, Sokmensuer C, Sivri B. Enteroscopic findings of celiac disease and their correlation with mucosal histopathologic changes. Comput Biol Med 2015;65:315-319.

11. Waterman M, Eliakim R. Capsule enteroscopy of the small intestine. Abdom Imaging 2009;34:452-458.

12. Zhong J, Ma T, Zhang C, et al. A retrospective study of the application on double-balloon enteroscopy in 378 patients with suspected small-bowel diseases. Endoscopy 2007;39:208-215.

13. Munn Z, Moola S, Riitano D, Lisy K. The development of a critical appraisal tool for use in systematic reviews addressing questions of prevalence. Int J Health Policy Manag 2014;3:123-128.

14. Meng Q, Xin L, Liu W, et al. Diagnosis and treatment of autoimmune pancreatitis in China: a systematic review. PLoS One 2015;10:e130466.

15. Inamdar S, Slattery E, Sejpal DV, et al. Systematic review and

meta-analysis of single-balloon enteroscopy-assisted ERCP in patients with surgically altered GI anatomy. Gastrointest Endosc 2015;82:9-19.

16. May A, Färber M, Aschmoneit I, et al. Prospective multicenter trial comparing push-and-pull enteroscopy with the single- and double-balloon techniques in patients with small-bowel disorders. Am J Gastroenterol 2010;105:575581.

17. Lenz P, Domagk D. Double- vs. single-balloon vs. spiral enteroscopy. Best Pract Res Clin Gastroenterol 2012;26:303313.

18. Hartmann D, Eickhoff A, Tamm R, Riemann JF. Balloonassisted enteroscopy using a single-balloon technique. Endoscopy 2007;39 Suppl 1:E276.

19. Efthymiou M, Desmond PV, Brown G, et al. SINGLE-01: a randomized, controlled trial comparing the efficacy and depth of insertion of single- and double-balloon enteroscopy by using a novel method to determine insertion depth. Gastrointest Endosc 2012;76:972-980.

20. Gong W, Zhi FC, Bai Y, et al. Single-balloon enteroscopy for small bowel diseases: results from an initial experience at a single Chinese center. J Dig Dis 2012;13:609-613.

21. Li X, Zhao YJ, Dai J, et al. Carbon dioxide insufflation improves the intubation depth and total enteroscopy rate in single-balloon enteroscopy: a randomised, controlled, double-blind trial. Gut 2014;63:1560-1565.

22. Xu N, Yu Z, Cao X, Wang Z, Yan M. Characteristics of nonsteroidal anti-inflammatory drugs (NSAIDs)-induced small bowel injury identified by single-balloon endoscopy or capsule endoscopy. Med Sci Monit 2017;23:5237-5245.

23. Aktas H, de Ridder L, Haringsma J, Kuipers EJ, Mensink PB. Complications of single-balloon enteroscopy: a prospective evaluation of 166 procedures. Endoscopy 2010;42:365-368.

24. Sethi S, Cohen J, Thaker AM, et al. Prior capsule endoscopy improves the diagnostic and therapeutic yield of singleballoon enteroscopy. Dig Dis Sci 2014;59:2497-2502.

25. Lenz P, Meister T, Manno M, et al. CO2 insufflation during single-balloon enteroscopy: a multicenter randomized controlled trial. Endoscopy 2014;46:53-58.

26. Pinho R, Mascarenhas-Saraiva M, Mão-de-Ferro S, et al. Multicenter survey on the use of device-assisted enteroscopy in Portugal. United European Gastroenterol J 2016;4:264274.

27. Murino A, Nakamura M, Despott EJ, Fraser C. Factors associated with reduced insertion depth at double balloon enteroscopy: a retrospective, multivariate analysis. Dig Liver Dis 2014;46:956-958.

28. Decker GA, Crowell MD, Das A, et al. Predictors of insertion depth at double balloon enteroscopy (DBE). Gastrointest Endosc 2009;69:AB309-AB310.

29. Wadhwa V, Sethi S, Tewani S, et al. A meta-analysis on ef- 
ficacy and safety: single-balloon vs. double-balloon enteroscopy. Gastroenterol Rep (Oxf) 2015;3:148-155.

30. Kim TJ, Kim ER, Chang DK, Kim YH, Hong SN. Comparison of the efficacy and safety of single- versus doubleballoon enteroscopy performed by endoscopist experts in single-balloon enteroscopy: a single-center experience and meta-analysis. Gut Liver 2017;11:520-527.

31. Domagk D, Mensink P, Aktas H, et al. Single- vs. doubleballoon enteroscopy in small-bowel diagnostics: a randomized multicenter trial. Endoscopy 2011;43:472-476.

32. Takano N, Yamada A, Watabe H, et al. Single-balloon versus double-balloon endoscopy for achieving total enteroscopy: a randomized, controlled trial. Gastrointest Endosc 2011;73:734-739.

33. Lipka S, Rabbanifard R, Kumar A, Brady P. Single versus double balloon enteroscopy for small bowel diagnostics: a systematic review and meta-analysis. J Clin Gastroenterol 2015;49:177-184.

34. Tanaka S, Mitsui K, Yamada Y, et al. Diagnostic yield of double-balloon endoscopy in patients with obscure GI bleeding. Gastrointest Endosc 2008;68:683-691.

35. Kawamura T, Yasuda K, Tanaka K, et al. Clinical evaluation of a newly developed single-balloon enteroscope. Gastrointest Endosc 2008;68:1112-1116.

36. Ohtsuka K, Kashida H, Kodama K, Mizuno K, Inoue H, Kudo S. Diagnosis and treatment of small bowel diseases with a newly developed single balloon endoscope. Dig Endosc 2008;20:134-137.

37. Tsujikawa T, Saitoh Y, Andoh A, et al. Novel single-balloon enteroscopy for diagnosis and treatment of the small intestine: preliminary experiences. Endoscopy 2008;40:11-15.

38. Ramchandani M, Reddy DN, Gupta R, et al. Diagnostic yield and therapeutic impact of single-balloon enteroscopy: series of 106 cases. J Gastroenterol Hepatol 2009;24:1631-1638.

39. Barth BA, Channabasappa N. Single-balloon enteroscopy in children: initial experience at a pediatric center. J Pediatr Gastroenterol Nutr 2010;51:680-684.

40. Dutta AK, Sajith KG, Joseph AJ, Simon EG, Chacko A. Learning curve, diagnostic yield and safety of single balloon enteroscopy. Trop Gastroenterol 2012;33:179-184.

41. Prachayakul V, Deesomsak M, Aswakul P, Leelakusolvong $S$. The utility of single-balloon enteroscopy for the diagnosis and management of small bowel disorders according to their clinical manifestations: a retrospective review. BMC Gastroenterol 2013;13:103.

42. Oliva S, Pennazio M, Cohen SA, et al. Capsule endoscopy followed by single balloon enteroscopy in children with obscure gastrointestinal bleeding: a combined approach. Digest Liver Dis 2015;47:125-130.

43. Marques M, Santos-Antunes J, Coelho R, et al. Single-balloon enteroscopy efficacy and degree of concordance with noninvasive evaluation of small bowel. Endosc Int Open 2017;5:E96-E102.

44. Vargo J, Upchurch B, Dumot J, Zuccaro G, Stevens T, Santisi JA. Clinical utility of the Olympus single balloon enteroscope: the initial U.S. experience. Gastrointest Endosc 2007;65:AB90

45. Vere CC, Foarfã C, Streba CT, Cazacu S, Pârvu D, Ciurea T. Videocapsule endoscopy and single balloon enteroscopy: novel diagnostic techniques in small bowel pathology. Rom J Morphol Embryol 2009;50:467-474.

46. Frantz DJ, Dellon ES, Grimm IS, Morgan DR. Single-balloon enteroscopy: results from an initial experience at a U.S. tertiary-care center. Gastrointest Endosc 2010;72:422-426.

47. Trifan A, Singeap AM, Cojocariu C, Sfarti C, Tarcoveanu E, Georgescu S. Single-balloon enteroscopy following videocapsule endoscopy for diagnosis of the small bowel tumors: preliminary experiences. Chirurgia (Bucur) 2010;105:211217.

48. Riccioni ME, Urgesi R, Cianci R, Spada C, Nista EC, Costamagna G. Single-balloon push-and-pull enteroscopy system: does it work? A single-center, 3-year experience. Surg Endosc 2011;25:3050-3056.

49. Alderlieste YA, Rauws EA, Mathus-Vliegen EM, Fockens P, Dekker E. Prospective enteroscopic evaluation of jejunal polyposis in patients with familial adenomatous polyposis and advanced duodenal polyposis. Fam Cancer 2012;12:5156.

50. Di Nardo G, Oliva S, Aloi M, et al. Usefulness of single-balloon enteroscopy in pediatric Crohn's disease. Gastrointest Endosc 2012;75:80-86.

51. Kushnir VM, Tang M, Goodwin J, et al. Long-term outcomes after single-balloon enteroscopy in patients with obscure gastrointestinal bleeding. Dig Dis Sci 2013;58:2572-2579.

52. Baijal R, Kumar P, Gupta DT, Shah N, Kulkarni S, Doshi S. Single-balloon enteroscopy: a single-center experience of 48 procedures. Indian J Gastroenterol 2014;33:55-58.

53. Davis-Yadley AH, Lipka S, Rodriguez AC, et al. The safety and efficacy of single balloon enteroscopy in the elderly. Therap Adv Gastroenterol 2015;9:169-179.

54. Holman N, Wallace K, Moore JM, Brock AS. Open-access single balloon enteroscopy: a tertiary care experience. South Med J 2015;108:739-743.

55. Minamino H, Machida H, Tominaga K, et al. Rectal biopsy, rather than ileal, is appropriate to confirm the diagnosis of early gastrointestinal graft-versus-host disease. Scand J Gastroenterol 2015;50:1428-1434.

56. Christian KE, Kapoor K, Goldberg EM. Performance characteristics of retrograde single-balloon endoscopy: a single center experience. World J Gastrointest Endosc 2016;8:501507.

57. Ma J, Wang Y, Xu X, et al. Capsule endoscopy and single- 
balloon enteroscopy in small bowel diseases: competing or complementary? World J Gastroenterol 2016;22:1062510630.

58. Ooka S, Kobayashi K, Kawagishi K, et al. Roles of capsule endoscopy and single-balloon enteroscopy in diagnosing unexplained gastrointestinal bleeding. Clin Endosc 2016;49:5660.

59. Haanstra JF, Al-Toma A, Dekker E, et al. Incidence of small bowel neoplasia in Lynch syndrome assessed by video cap- sule endoscopy. Endosc Int Open 2017;5:E622-E626.

60. Lu Z, Qi Y, Weng J, et al. Efficacy and safety of single-balloon versus double-balloon enteroscopy: a single-center retrospective analysis. Med Sci Monit 2017;23:1933-1939.

61. Moran RA, Barola S, Law JK, et al. A randomized controlled trial comparing the depth of maximal insertion between anterograde single-balloon versus spiral enteroscopy. Clin Med Insights Gastroenterol 2018;11:419549375. 